\title{
Efeitos Cardiovasculares Agudos da Exposição ao Ambiente Microgravitacional
}

\author{
Paulo Eustáquio de Brito Santos, Martin Hernán Bonamino
}

Rio de Janeiro, RJ

Com a perspectiva do aumento crescente de missões espaciais tripuladas de curta e longa duração, torna-se cada vez mais importante o conhecimento dos efeitos do ambiente espacial modificado - notadamente o interior das naves espaciais - sobre o organismo humano. Não subestimando a importância dos outros fatores ambientais como as radiações cósmicas, a atmosfera artificial das espaçonaves (e das vestimentas para as atividades extraveiculares), a ausência de ciclo claro/escuro natural e o confinamento, a virtual ausência de gravidade é certamente a maior causa de alterações fisiológicas e doenças reconhecidas até hoje nos astronautas e animais de experimentação lançados ao espaço. Neste contexto, não é demais lembrar que as formas de vida na Terra evoluíram durante milhões de anos em presença de gravidade $1(1 \mathrm{G})$, de modo que sua morfologia e fisiologia se desenvolveram no sentido de melhor adequação possível a este valor.

No que diz respeito ao aparelho cardiovascular, a abolição da gravidade manifesta-se principalmente pelo fim do peso da coluna líquida dentro dos vasos sangüíneos, ou seja, ausência da pressão hidrostática $\left(\mathrm{P}_{\text {hid }}\right)$, com importantes repercussões sobre a dinâmica dos sistemas venoso, capilar e arterial. Além disso, a função circulatória torna-se ainda mais alterada pela anulação da compressão extrínseca sobre os vasos normalmente exercida pelo peso dos tecidos e órgãos adjacentes. A longo prazo somam-se a estes fatores o descondicionamento físico e a atrofia muscular ${ }^{1}$, aumentando assim o número de variáveis que influenciam o comportamento do sistema cardiovascular. Finalmente, é importante lembrar que a mudança do ambiente terrestre

Instituto de Biofísica Carlos Chagas Filho - Laboratório de Eletrofisiologia do Hospital Clementino Fraga Filho - UFRJ - Departamento de Bioquímica Médica UFRJ - Instituto Nacional do Câncer

Correspondência: Paulo Eustáquio de Brito Santos - Instituto de Biofísica Carlos Chagas Filho - Centro de Ciências da Saúde, Bloco G - UFRJ - Ilha do Fundão 21941-900 - Rio de Janeiro, RJ - E-mail: britobr@hotmail.com

Recebido para publicação em 9/8/01

Aceito em 1/11/01 para o microgravitacional tem repercussões sobre o comportamento intrínseco do sistema nervoso, onde fenômenos de sensibilização e habituação (processo de aprendizado) estão constantemente em curso, modificando as respostas autonômicas no sentido de melhor adaptação ao novo ambiente.

O presente artigo tem por objetivo discutir os efeitos imediatos e a curto prazo da abolição da gravidade sobre o sistema cardiovascular humano, assim como as respostas adaptativas agudas do organismo, visando à homeostase circulatória. Este processo é denominado pelos fisiologistas de "aclimatação aguda" à microgravidade *. Na inexistência de uma periodização formal, por respostas agudas devem ser entendidos aqui os processos fisiológicos que tomam lugar no período compreendido entre a imediata instalação da gravidade zero $(0 \mathrm{G})$ até os primeiros dias de sua vigência.

\section{Estudo da função cardiovascular em microgravidade}

Os efeitos da microgravidade sobre o sistema cardiovascular têm sido estudados em vôos espaciais de curta e longa duração, assim como em experimentos de simulação fora do ambiente espacial. No que se refere aos vôos, os experimentos têm sido realizados na presença de uma série de fatores limitantes, como as restrições de espaço físico, tempo e equipamentos, a ausência de condições controles ótimas em função, por exemplo, do estresse psicológico, da postura corporal na fase de pré-lançamento, das grandes acelerações experimentadas no lançamento e na reentrada, e do emprego de medidas preventivas contra os efeitos deletérios, já conhecidos da microgravidade. Infelizmente, a pesquisa

\footnotetext{
* A rigor, não seria fisicamente correto falar em "microgravidade" ou "ausência de gravidade", uma vez que a grande maioria dos dados foi obtida numa altitude de 200 a $500 \mathrm{~km}$, onde a força gravitacional é ainda bastante forte (cerca de 80 a $94 \%$ do valor normal). Entretanto, como os corpos em órbita tendem a seguir em linha reta em função de sua inércia, a gravidade se torna igualada para cada velocidade e cada altitude, resultando num efeito de "abolição" da gravidade.
} 
com cobaias no espaço apresenta várias dificuldades e limitações. Animais pequenos não estão sujeitos - e portanto, não adaptados evolutivamente - às grandes pressões hidrostáticas encontradas no sistema vascular humano na posição vertical na Terra, o que dificulta a extrapolação dos resultados para nossa espécie. Experimentos com animais de grande e médio porte apresentam dificuldades óbvias de transporte e manutenção nos vôos espaciais. No último caso, boa parte das limitações pode ser obviada nos experimentos de simulação na Terra nos quais os animais podem ser mantidos em posição equivalente à nossa por períodos relativamente longos.

No que se refere aos efeitos imediatos da microgravidade, uma grande quantidade de dados tem sido obtida com experimentos de simulação em aviões durante a realização do chamado vôo parabólico, no qual a aceleração desenvolvida na trajetória parabólica cancela a aceleração gravitacional (fig. 1). Infelizmente, o efeito de anulação da gravidade é muito fugaz, durando não mais que $20 \mathrm{a} 30 \mathrm{~s}^{2}$.

Para simular os eventos que ocorrem no prazo de horas e dias em gravidade zero, os fisiologistas têm utilizado com freqüência o repouso no leito com cabeceira rebaixada a 5$10^{\circ}$ (head down tilt [HDT]), a fim de reduzir drasticamente as diferenças de pressão hidrostática entre as partes superior e inferior do corpo, e ainda favorecer, como ocorre no espaço, o acúmulo de sangue no tórax. Este modelo tem como inconveniência a não abolição da força da gravidade, permanecendo os efeitos desta sobre os fluidos no sentido ântero-posterior do corpo.

Outra simulação muito freqüente, principalmente entre os pesquisadores russos, é a "imersão seca em água”, na qual o indivíduo submerso fica protegido dos efeitos deletérios do contato prolongado com a água por meio de vestimenta isolante. Neste caso, a força da gravidade é antagonizada pelo empuxo provocado pela submersão. Este modelo

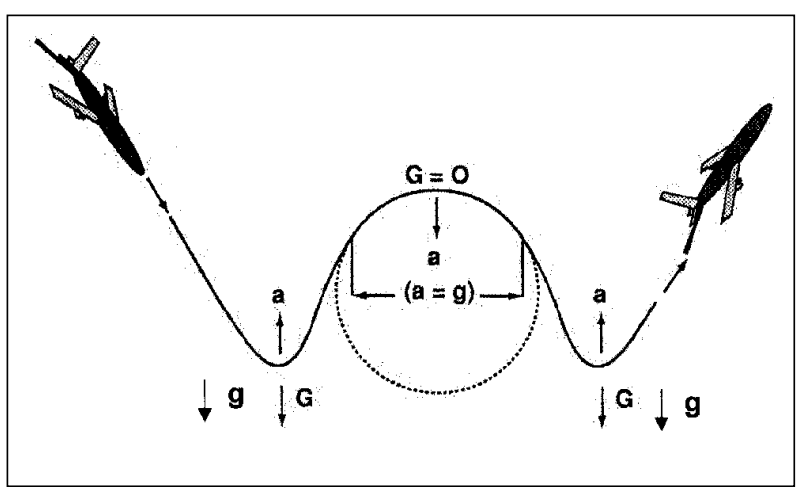

Fig. 1 - Desenho esquemático do chamado vôo parabólico ou kepleriano. Quando o avião inicia a trajetória de subida, sua aceleração (a) direciona-se para cima e os passageiros sofrem "aceleração inercial" (-a) para baixo no sentido da aceleração da gravidade (g), resultando em força inercial (G) para baixo. Ao penetrar na região delimitada pela linha pontilhada (região da parábola), os motores são desligados e, pela inércia, os passageiros são projetados para a frente do avião de modo que o componente de sua "aceleração inercial" na vertical tende a anular a aceleração da gravidade, causando $G=0$. Na metade descendente da parábola, os passageiros são acelerados para a traseira do avião levando novamente ao cancelamento da aceleração da gravidade. Os estudos de simulação são realizados no período de "gravidade zero" que dura em torno de 20 a $30 \mathrm{~s}^{1}$. apresenta, como grande vantagem, a possibilidade da livre movimentação, ao contrário do HDT, onde a mobilidade no leito é bastante limitada. Entretanto, como no modelo HDT, a gravidade não é anulada, de modo que persistem gradientes de pressão hidrostática, ainda que sobremaneira atenuados.

\section{Fundamentos teóricos}

Na superfície da Terra, o efeito do campo gravitacional sobre os líquidos tem uma enorme importância na biofísica e fisiologia do sistema cardiovascular. Esta importância se deve ao fato de que, sendo um circuito fechado preenchido por líquido, o sistema cardiovascular está continuamente sujeito a variações de pressão transmural causadas por alterações da pressão hidrostática que acompanham as mudanças posturais.

A pressão hidrostática $\left(P_{\text {hid }}\right)$ pode ser expressa em função do peso, produto da massa da coluna líquida $(m)$ pela aceleração da gravidade $(G)$, dividido pela área $(A)$ na qual a pressão está sendo exercida: $P_{\text {hid }}=m G / A$

Multiplicando-se os dois termos pela altura $h$ da coluna, o denominador passa a indicar volume $(V)$ e teremos a relação $m / V$, que pode ser substituída pela densidade do líquido $(\rho)$, de modo que $P_{\text {hid }}=\rho G h$

Assim sendo, considerando-se $G=9,8 \mathrm{~m} \cdot \mathrm{s}^{-2}$ na superfície da Terra e a densidade do sangue humano igual a $1,06 \times 10^{3} \mathrm{~kg} \cdot \mathrm{m}^{-3}$, para um indivíduo de pé, um ponto situado a 1,20m abaixo do coração (por exemplo no tornozelo) terá, em relação a este, uma pressão hidrostática de $12.466 \mathrm{~Pa} \mathrm{ou}$ $94 \mathrm{mmHg}$.

Por sua vez, a pressão transmural $\left(P_{T}\right)$ em um ponto do sistema é dada pela soma da pressão dinâmica gerada pelo bombeamento cardíaco contra a resistência periférica ao fluxo (produto do fluxo, $Q$, pela resistência, $R$ ), da pressão média de enchimento do sistema circulatório $\left(P_{E C}\right)$, de um componente de pressão gerado por compressão extrínseca do vaso $\left(P_{\text {ext }}\right)$ e da pressão hidrostática $(\rho G h)$ neste ponto: $P_{T}=Q R+P_{E C}+P_{e x t}+\rho g h$

Se desprezarmos $P_{\text {ext }}$ e considerarmos uma $P_{T}$ média de $90 \mathrm{mmHg}$ no início da aorta (mesma altura do coração), a pressão transmural em um segmento de artéria situado $1,20 \mathrm{~m}$ abaixo do coração será, para o indivíduo deitado $(\Delta h \approx 0$, em relação ao coração), ligeiramente $<90 \mathrm{mmHg}$ - por exemplo, $88 \mathrm{mmHg}$ - em função da dissipação de energia ao longo do sistema. Para o mesmo indivíduo em posição ortostática, o valor da $P_{T}$ média será acrescido de $94 \mathrm{mmHg}$ referentes à $P_{\text {hid }}$, perfazendo um total de $182 \mathrm{mmHg}$. O mesmo se aplica ao território venoso. Se em posição deitada a $P_{T}$ for de $12 \mathrm{mmHg}$ para um ponto situado a $1,20 \mathrm{~m}$ do coração, ela se elevará para $106 \mathrm{mmHg}$ na posição ortostática.

Do ponto de vista prático, o cálculo da $\mathrm{P}_{\text {hid }}$ é feito geralmente em relação a um nível de referência zero situado na altura do coração, mais precisamente no nível da valva tricúspide. Este nível foi escolhido porque, em condições normais, independentemente da posição assumida, o bombeamento cardíaco impede qualquer acúmulo de sangue 
proveniente das veias cavas, de forma que a pressão média do átrio direito tende a zero, igualando-se à pressão atmosférica. Deste modo, para pontos localizados $30 \mathrm{~cm}$ acima e abaixo do coração, $\mathrm{a}_{\text {hid }}$ será de $-23 \mathrm{e}+23 \mathrm{mmHg}$, respectivamente. Formalmente, podemos definir o nível zero, também denominado de "nível de indiferença hidrostática", como o local da circulação cuja pressão hidrostática permanece constante a despeito de mudanças posturais do organismo em relação ao vetor da aceleração gravitacional ${ }^{1,3}$. Na verdade, devido à complacência vascular, pequenos aumentos da $\mathrm{P}_{\text {hid }}$ são neutralizados, de forma que o nível de indiferença hidrostática tende a situar-se um pouco abaixo do nível mencionado. Por ser mais complacente do que o sistema arterial, o sistema venoso possui, comparativamente, um nível de indiferença hidrostática mais distante (no sentido caudal) do coração ${ }^{1}$.

Em condições de gravidade normal, quando uma pessoa assume a posição ereta, o aumento da $\mathrm{P}_{\text {hid }}$ na porção corporal inferior leva a uma distensão das veias, promovendo armazenamento de sangue nestas e, conseqüentemente, redução do retorno venoso para o coração. Além disso, a elevada pressão hidrostática capilar favorece a saída de líquido para o espaço intersticial, reduzindo o volume sangüíneo, o que diminui ainda mais o retorno venoso. Uma vez que passamos grande parte de nosso tempo de vigília nesta posição, é razoável afirmar que há uma tendência natural ao acúmulo de sangue na região abaixo do nível de indiferença hidrostática. Ao contrário, quando passamos da posição ortostática ou sentada para a posição deitada, a $\mathrm{P}_{\mathrm{T}}$ nas veias dos membros inferiores se torna bastante reduzida (pelo fim da $P_{\text {hid }}$ no eixo crânio-caudal), o que diminui acentuadamente a distensão vascular e aumenta o retorno venoso. Concomitantemente, a pressão capilar sofre a mesma redução, levando a uma menor filtração de líquido para o interstício, o que contribui para o aumento do retorno venoso.

Efeitos opostos são esperados acima do nível de indiferença hidrostática. Se em ortostatismo o retorno venoso da cabeça é facilitado pelo peso da coluna líquida situada acima do coração, na posição de decúbito este fator é abolido, havendo então menor retorno venoso e acúmulo de sangue na região cefálica. No que se refere às artérias, a mudança da posição sentada ou de pé para a deitada refletese em aumento da pressão arterial, posto que o sangue proveniente do coração não sofre mais a oposição do vetor descendente $\mathrm{P}_{\text {hid }}$.

De acordo com o exposto acima, é fácil prever que, quando submetido agudamente à gravidade zero, o sistema cardiovascular humano apresentará um comportamento muito semelhante ao descrito para a posição deitada em $1 \mathrm{G}$, considerando-se que em ambas as situações o gradiente crânio-caudal de $\mathrm{P}_{\text {hid }}$ é abolido. Entretanto, como veremos adiante, o estudo da fisiologia cardiovascular espacial torna-se particularmente interessante na medida em que a anulação da $\mathrm{P}_{\text {hid }}$ em gravidade zero não reproduz todas as alterações hemodinâmicas observadas na passagem da posição ortostática para a deitada na Terra, sugerindo uma complexidade bem maior do que a prevista pelo simples fim da colu- na líquida vertical. Dentre os responsáveis pelas discrepâncias, destaca-se a ausência da compressão extrínseca dos vasos pelo peso dos órgãos. A longo prazo, a interpretação das respostas cardiovasculares se torna ainda mais complexa em função do descondicionamento físico e da atrofia muscular.

Conforme já bem estabelecido ${ }^{1,4-7}$, em relação à posição ereta na Terra, a abolição aguda da gravidade promove uma redistribuição do sangue no sentido de seu acúmulo nas regiões torácica e cefálica e redução nas regiões inferiores do corpo (fig. 2), de forma muito semelhante ao que ocorre quando passamos da posição ortostática para a de decúbito ${ }^{8,9}$. Neste sentido são comuns os relatos de congestão facial e "pernas de pássaro" (bird legs) pelos astronautas ${ }^{1,10,11}$, refletindo respectivamente o excesso de sangue na cabeça e a escassez nos membros inferiores.

\section{Hemodinâmica em microgravidade}

Circulação central: Com relação à circulação central, a hipótese do aumento de volume sangüíneo foi reforçada por exames ecocardiográficos que demonstraram, no $1^{\circ}$ dia em órbita, aumento dos volumes diastólico final e sistólico do ventrículo esquerdo em comparação não só com os valores obtidos em posição ereta (maiores diferenças), mas também com os registrados na posição supina de pré-lançamento (menores diferenças) ${ }^{11-13}$. Na simulação por vôo parabólico, Johns e cols. ${ }^{14}$ não conseguiram resultados tão evidentes: apesar de registrarem, por ultrassonografia-Doppler, aumento da velocidade inicial de enchimento ( $23 \%$ ), do tempo de ejeção (3\%) e do volume sistólico (13\%) do ventrículo esquerdo, sugerindo aumento de pré-carga (e elevação do fluxo torácico), nenhuma alteração foi encontrada nas dimensões ventriculares ao final da diástole.

As alterações da volemia torácica foram também avaliadas por medidas de bioimpedância. No que se refere ao vôo parabólico ${ }^{15,16}$, quando a manobra era realizada com os voluntários de pé ou sentados, a impedância torácica se reduzia nitidamente, refletindo o aumento do volume líquido previsto teoricamente. Ao contrário, quando o teste era feito com os indivíduos em posição supina, a impedância aumentava durante o período de microgravidade, o que sugere que, no decúbito em $1 \mathrm{G}$, a quantidade de sangue no tórax é ainda maior do que em condições de gravidade zero. Dados obtidos em missões espaciais confirmam estes resultados: ao assumir a posição supina de pré-lançamento, a impedância torácica dos astronautas diminuiu como era esperado; a partir daí, no entanto, ela passou a apresentar uma elevação constante e gradual desde o pré-lançamento até as primeiras órbitas, não sendo detectadas alterações marcantes durante a entrada em $0 \mathrm{G}^{17}$.

Considerando o desvio de sangue no sentido tóracocefálico, seria natural esperar um aumento da pressão venosa central logo após a entrada em gravidade zero. Entretanto, para a surpresa dos fisiologistas, esta hipótese começou a ser questionada em meados dos anos oitenta, quando 


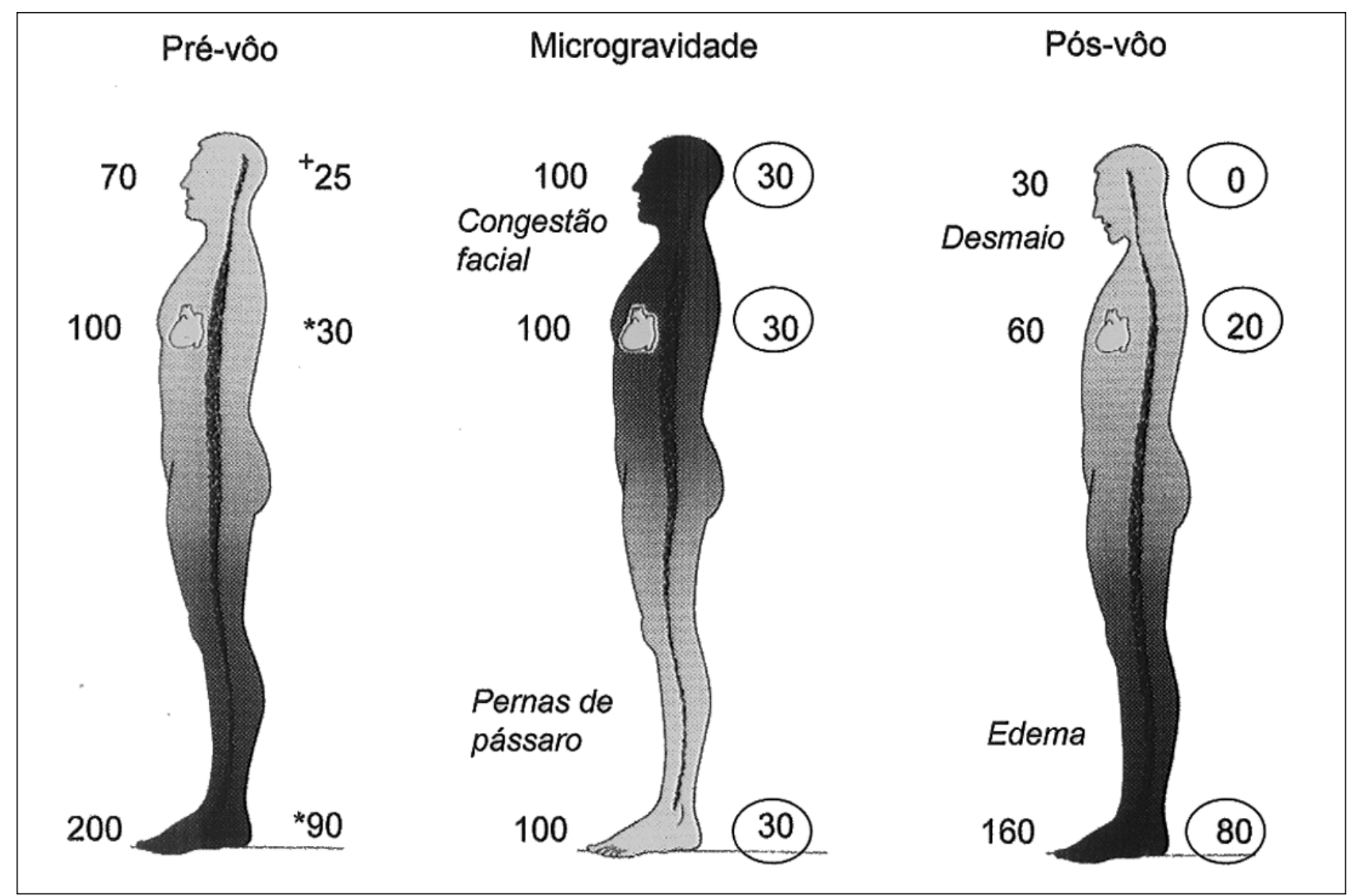

Fig. 2 - Distribuição prevista do fluido tissular (sombreamento) e das pressões arterial média (valores de frente para as figuras humanas) e capilar (valores nas costas das figuras) ao nível da cabeça, do coração e dos pés, em posição ortostática na Terra antes (pré-vôo) e após (pós-vôo) um vôo espacial, e na condição de microgravidade. Observe que, em 0G, o sangue desloca-se para as regiões torácica e cefálica causando congestão facial e "pernas de pássaro". Concomitantemente, ocorre aumento da pressão arterial (PA) e capilar (PC) na cabeça e redução de ambas ao nível dos pés. No retorno à Terra, observam-se diminuição da volemia, acúmulo de sangue nos membros inferiores e redução generalizada da PA e PC. Obs.: ${ }^{+}$valor determinado por Parazynsly e cols. (8); * valores segundo Levick \& Michel (9); XX) valores inferidos; PA em mmHg. (Reproduzido com autorização e modificado de Hargens, Watenpaugh \& Breit: Control of circulatory function in altered gravitational fields. Physiologist 1992; 35(suppl): S80-3).

Kirsch e cols. ${ }^{18,19}$ mostraram redução da pressão em veias do antebraço entre 20 min e 10 dias de permanência em órbita. Posteriormente, medindo a pressão venosa central diretamente por meio de cateter intravenoso em um astronauta do ônibus espacial, Buckey e cols. ${ }^{12}$ encontraram, em relação aos valores na posição supina de pré-lançamento, redução de $10-15 \mathrm{cmH}_{2} \mathrm{O}$ imediatamente (1 $\mathrm{min}$ ) após entrada em gravidade zero e de $8-11 \mathrm{cmH}_{2} \mathrm{O}$ nas nove primeiras horas. Pouco depois, o mesmo grupo confirmou a diminuição da pressão venosa central em mais dois astronautas, logo após a entrada em microgravidade (fig. 3 ) até o momento em que os cateteres foram retirados, um com 10 e outro com $44 \mathrm{~h}$ de vôo ${ }^{13}$. Em outro estudo com medida direta da pressão venosa central $^{20}$, esta apresentou valores iguais ou inferiores aos do período controle (posição supina na Terra) durante todo o período de registro em $0 \mathrm{G}$ (primeiras 3 h em órbita).

Estudos sobre a pressão venosa central foram também conduzidos nos modelos de microgravidade simulada. No caso da manobra HDT, os valores da pressão venosa central durante a inclinação foram iguais ou maiores do que os obtidos na posição supina horizontal ${ }^{21-24}$ contrariando, portanto, a tendência predominante no ambiente espacial. No que tange ao vôo parabólico, o mesmo grupo de fisiolo- gistas relatou tanto aumento $\left(+2,4 \mathrm{cmH}_{2} \mathrm{O}\right)^{25}$, quanto redução $\left(-2,0 \mathrm{cmH}_{2} \mathrm{O}\right)^{20}$ dos valores da pressão venosa central, o que foi creditado a diferenças metodológicas: enquanto na segunda investigação os indivíduos estudados permaneceram o tempo todo deitados, na primeira eles alternaram entre a posição supina (medidas controles em $1 \mathrm{G}$ ) e a sentada (medidas realizadas durante a manobra parabólica). No modelo de imersão em água, os resultados imediatos mostraram nítido aumento da pressão venosa central ${ }^{26}$.

Os resultados obtidos com a medida direta da pressão venosa central no espaço, dificilmente criticáveis em função do seu rigor metodológico, vieram justificar as reduções da pressão venosa no antebraço descritas anteriormente ${ }^{18,19} \mathrm{e}$, devido a sua difícil explicação, passaram a constituir o que se poderia chamar "calcanhar de Aquiles" da fisiologia espacial no que diz respeito ao sistema cardiovascular.

A justificativa para a redução da pressão venosa central concomitante a um aumento da volemia central ainda não é conhecida, mas poderia envolver alteração da complacência circulatória efetiva. Neste sentido, uma possível explicação seria a remoção (no ambiente microgravitacional) da compressão vascular exercida pelo peso dos órgãos, ou seja, da $\mathrm{P}_{\text {ext }}$. Isto causaria diminuição das pressões intravasculares, 


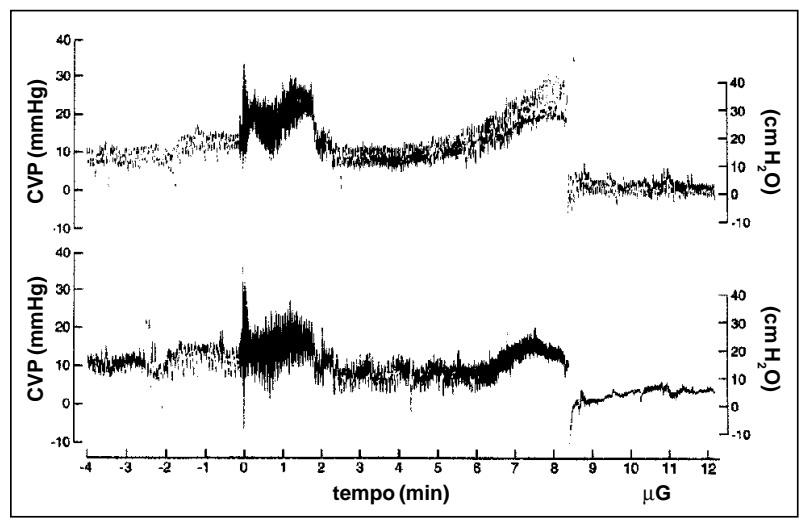

Fig. 3 - Registro contínuo da pressão venosa central (CVP) em dois astronautas do ônibus espacial americano obtido no intervalo de $4 \mathrm{~min}$ antes do lançamento até $4 \mathrm{~min}$ após a entrada em microgravidade. Observe a nítida queda da CVP logo após a entrada em órbita. As oscilações de baixa frequência nos $2 \mathrm{~min}$ iniciais do lançamento se deveram provavelmente à forte compressão torácica no sentido ântero-posterior provocada pelas forças de aceleração. A CVP foi medida por meio de cateter posicionado na veia cava superior ao nível do átrio direito, acoplado a um transdutor de pressão externo. (Reproduzido com autorização de Buckey, Gaffney, Lane, Levine, Watenpaugh, Wright, Yancy, Meyer \& Blomqvist: Central venous pressure in space. J Appl Physiol 1996; 81: 19-25)

principalmente na microcirculação e nas veias de tecidos relativamente complacentes como as circulações cutânea e esplâncnica, levando então a diminuição da pressão venosa central ${ }^{1}$. Outra hipótese seria baseada em alterações geométricas experimentadas pelo tórax em gravidade zero. Neste sentido, Estenne e cols. ${ }^{27}$ mostraram que, com a passagem da posição supina em $1 \mathrm{G}$ (posição de pré-lançamento) para a microgravidade, o tórax tende a assumir um formato mais circular e menos elipsóide. Uma vez que a área máxima contida em um mesmo perímetro é o círculo, presume-se que o "cilindro" torácico passe a apresentar maior área de secção reta e, conseqüentemente, maior volume, o que acarretaria queda em todas as pressões intratorácicas, entre elas as intracardíacas e intravasculares. Recentemente, realizando simulações em modelo matemático do sistema cardiovascular, White e Blomqvist ${ }^{28}$ confirmaram a alteração da forma do tórax pela remoção do peso de sua parede, o que propiciaria aumento do volume torácico e, conseqüentemente, redução da pressão intrapleural. Com isto, o sangue seria mobilizado em direção ao tórax, a pressão transmural de enchimento cardíaco aumentaria e haveria redução da pressão venosa central devido à dilatação dos vasos intratorácicos. Uma terceira possibilidade seria uma redução da pressão de enchimento circulatória conseqüente a hipovolemia existente nos primeiros dias no espaço ${ }^{1,4,29}$ (ver adiante). Por outro lado, é pouco provável que a queda da pressão venosa central seja provocada por redução do tônus da musculatura lisa venosa, uma vez que a maioria dos resultados tem sugerido a presença de vasoconstrição nos primeiros dias em gravidade zero, pelo menos no que se refere aos membros inferiores ${ }^{1,30}$. Da mesma forma, uma redução da pressão venosa central causada por aumento da contratilidade cardíaca parece descartada pela análise da função mecânica do miocárdio a partir de ecocardiogramas realizados no espaço ${ }^{13}$.

Com relação ao volume plasmático, sabe-se hoje que ele sofre uma diminuição de 10 a $25 \%$ nas primeiras 24 a $48 \mathrm{~h}$ no espaço, com ligeira recuperação ao longo da primeira semana ${ }^{29,31-33}$. Daí para frente, permanece estabilizado em pouco menos de $10 \%$ abaixo dos níveis normais ${ }^{29}$. Apesar de conhecida há bastante tempo, a redução do volume plasmático ainda não é de todo explicada. Baseando-se no conhecimento do desvio crânio-torácico do sangue e nos resultados dos modelos de simulação por HDT e imersão em água ${ }^{34-36}$, foi previsto um aumento da diurese nos primeiros dias de vôo em função de respostas autonômicas e endócrinas desencadeadas pelo estímulo de receptores cardiopulmonares de baixa pressão ${ }^{1,6}$. Entretanto, no ambiente espacial, tal aumento nunca foi demonstrado ${ }^{1,29}$, o que originou a hipótese de que, ao contrário, a hipovolemia poderia ser conseqüente a uma redução da ingestão hídrica. De fato, o volume de água ingerido se reduz em cerca de 11 /dia nos primeiros 2 dias no espaço ${ }^{37,38}$ (fig. 4). A diminuição da ingestão, por sua vez, poderia ser conseqüência da recusa voluntária nas horas que antecedem o lançamento ou da inibição da sede pela cinetose espacial** (space motion sickness) ${ }^{29}$, que acomete $50 \%$ dos cosmonautas nos primeiros 2-3 dias de vôo ${ }^{1,6}$. Além disso, tem sido proposto que a redução da

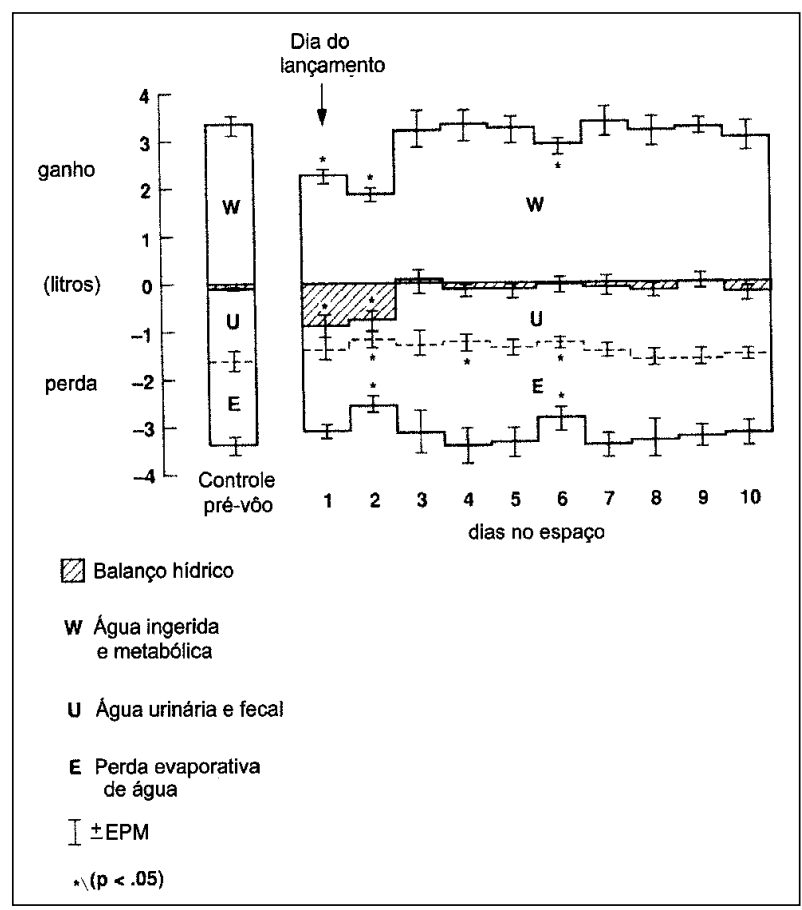

Fig. 4 - Balanço hídrico diário em 9 tripulantes do Skylab durante os 10 primeiros dias no espaço. No $1^{\circ} \mathrm{e} 2^{\circ}$ dias, a ingestão de água se mostrou reduzida em cerca de 11 / dia, o que causou um balanço hídrico negativo apesar da diminuição concomitante da diurese. A partir do dia 3, o padrão de ganho e perda de água apresentou uma tendência à normalização, com alterações apenas esporádicas. $* \mathrm{P}<0,05$ em relação aos respectivos controles pré-vôo. (Reproduzido com autorização e modificado de Leach, Altchuler \& Cintron-Trevino: The endocrine and metabolic responses to space flight. Med Sci Sports Exerc 1983; 15: 432-440).

\footnotetext{
** Síndrome semelhante ao "enjôo de movimento", desencadeada na ausência de gravidade e que se caracteriza por vertigem discreta, cefaléia, mal-estar, letargia, anorexia, náuseas e vômitos.
} 
ingestão se deva, em parte, ao fenômeno da desidratação involuntária, definida como um descompasso entre a sede (e a conseqüente ingestão líquida) e a necessidade real de água do organismo, que ocorre em situações de estresse como exercício, calor, frio, imersão em água, altitude e, talvez, microgravidade ${ }^{39}$. Nos cosmonautas acometidos de cinetose, a desidratação pode ser ainda agravada pela perda líquida na forma de vômitos ${ }^{1}$.

Circulação dos membros inferiores: Com relação aos membros inferiores, é notável a drástica redução do fluxo sangüíneo nos primeiros dias em órbita, de modo que os mesmos adquirem o já mencionado aspecto de "pernas de pássaro" "1,11. Avaliações do volume dos membros inferiores por pletismografia circunferencial conduzidas nos projetos Skylab, Apollo-Soyus e nos ônibus espaciais revelaram, respectivamente, reduções (por membro inferior) de $931 \mathrm{ml}$ $(12,2 \%), 803 \mathrm{ml}(10 \%)$ e $1.026 \mathrm{ml}(11,6 \%)$ em comparação aos valores pré-vôo, sendo que as maiores perdas ocorreram no primeiro dia das missões como exemplificado na figura $5^{40}$. Nas simulações de microgravidade, a intensidade da redução foi menor: 2,6, 1,7 e 4,0\%, respectivamente para posição supina horizontal, $\mathrm{HDT}$ a $6^{\circ}$ e imersão horizontal em água ${ }^{41}$. A causa da alteração volumétrica tem sido creditada ao desvio imediato de sangue no sentido cefálico acompanhada de perda de fluido intersticial dos membros inferiores para o compartimento vascular ${ }^{40}$.

Considerando as altas pressões a que estão submetidos os tecidos dos membros inferiores na Terra, acredita-se que esse território seja um local de intensos processos regulatórios agudos e de aclimatação, ainda pouco conhecidos. Nos raros estudos conduzidos na fase de adaptação aguda realizados em um número muito pequeno de astronautas, as técnicas de Doppler ultrassônico e pletismografia de oclusão venosa mostraram redução do tempo de trânsito da onda de pulso ${ }^{42}$, aumento da resistência na artéria femo$\mathrm{ral}^{43}$, redução do fluxo e aumento da resistência arterial dos membros inferiores ${ }^{30}$, indicando assim a presença de vasoconstrição arterial. Coerentemente, Sulzman e cols. ${ }^{44}$ relataram uma queda de $7^{\circ} \mathrm{C}$ na temperatura cutânea do tornozelo de 2 macacos resus em vôo de três dias no biossatélite soviético Cosmos 1514.

No que diz respeito ao território venoso, trabalhos utilizando técnicas pletismográficas têm mostrado, em sua maioria, aumento da complacência venosa ${ }^{1,30}$, o que poderia ser explicado pela redução da compressão extrínseca dos vasos em função da ausência de peso dos tecidos e da diminuição do volume intersticial ${ }^{1}$. Por outro lado, uma redução do tônus da musculatura lisa como causa de aumento da complacência parece pouco provável, uma vez que os resultados obtidos no território arterial sugerem aumento do tônus simpático.

Circulação cerebral: No caso da circulação cerebral, é possível que o aumento agudo do fluxo sangüíneo previsto teoricamente possa ser atenuado ou mesmo impedido pela

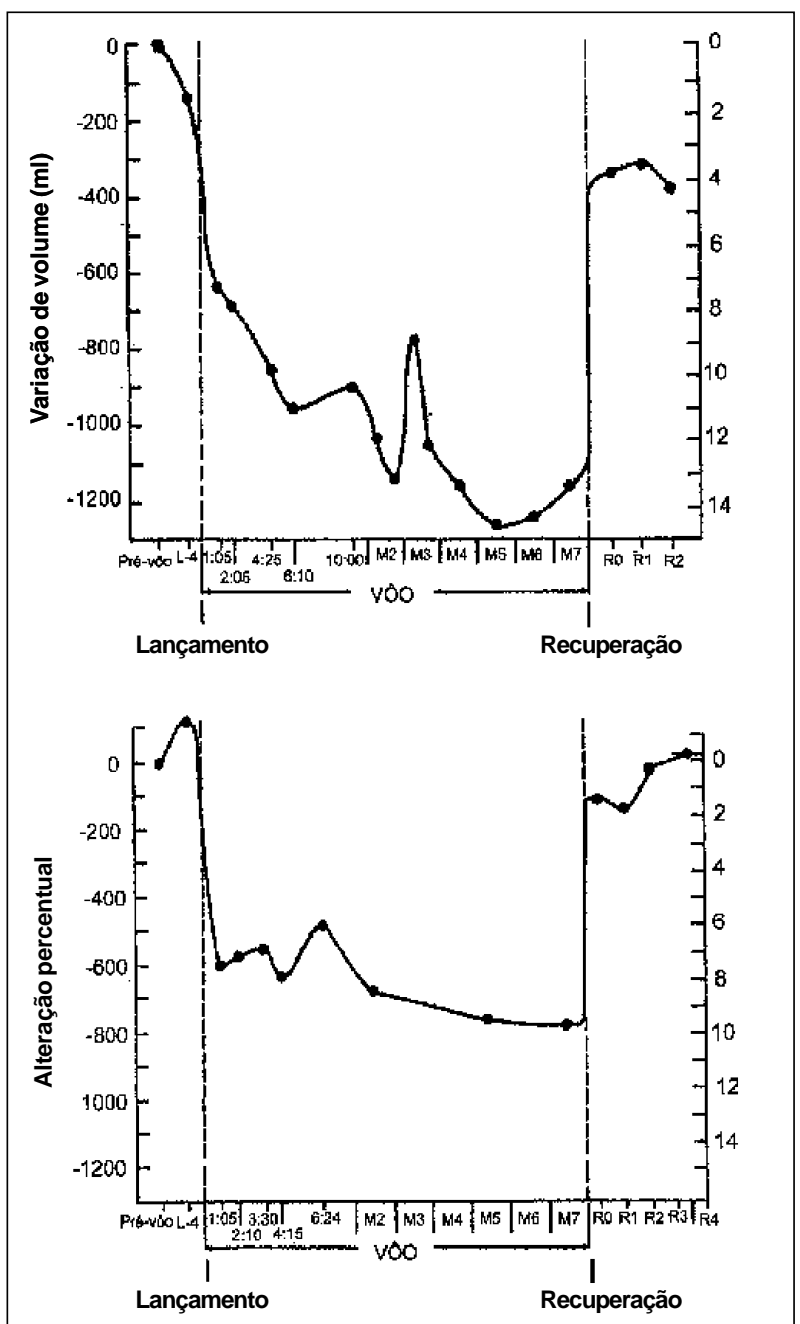

Fig. 5 - Evolução do volume do membro inferior de dois astronautas antes, durante e após uma permanência de sete dias no espaço. Em ambos os casos, observa-se uma acentuada redução de volume no primeiro dia da missão ( 7,5-9,5\%, 570-810ml), principalmente nas primeiras $4 \mathrm{~h}$ depois do lançamento, e uma recuperação rápida após o retorno. O volume foi determinado medindo-se várias circunferências ao longo da coxa e da perna e assumindo-se o membro inferior como um conjunto de cones truncados de alturas conhecidas delimitadas pelas referidas circunferências. Todas as medidas foram realizadas em ortostatismo. Obs.: L-4: 4 h antes do lançamento; M2 a M7: os números se referem ao dia da missão; R0, R1, R2, R3 e R4: dia do pouso, 1, 2, 3 e 4 dias após o pouso. (Reproduzido com autorização e modificado de Moore \& Thornton: Space shuttle inflight and postflight fluid shifts measured by leg volume changes. Aviat Space Environ Med 1987; 58(suppl): A91-6).

poderosa capacidade de autorregulação deste território ${ }^{45}$. Infelizmente, poucos dados consistentes existem sobre o fluxo cerebral em condições de microgravidade. Sintomas e sinais físicos sugestivos de congestão venosa craniana como "sensação de sangue fluindo para a cabeça" (especialmente durante o exercício ou após ingestão de grandes volumes líquidos), edema facial (descrito e fotografado), voz anasalada e distensão das veias da cabeça e do pescoço têm sido descritos com freqüência ${ }^{10,46,47}$, sugerindo que o fluxo cerebral esteja realmente aumentado logo após a entrada em microgravidade. Esta hipótese foi reforçada pela medida da pressão intra-ocular em um astronauta alemão do Spacelab, que revelou, em relação ao controle em posição sentada na Terra, um aumento de $92 \%$ aos 16 min de órbita, 
indicando provavelmente elevação da pressão sangüínea intracraniana ${ }^{48}$.

Com o objetivo de avaliar as alterações imediatas do fluxo cerebral em microgravidade, Bondare cols. ${ }^{49}$ utilizaram o Doppler transcraniano em manobras parabólicas e observaram, em indivíduos sentados, aumento transitório (5-10s) do fluxo na artéria cerebral média ao mesmo tempo que a pressão arterial e a freqüência cardíaca eram reduzidas. O caráter temporário da elevação do fluxo foi interpretado em função da poderosa autorregulação vascular da circulação cerebral.

Os estudos hemodinâmicos no espaço, por sua vez, têm sido controversos. Utilizando a técnica de Doppler ultrassônico transcraniano em quatro astronautas do ônibus espacial, Bagian e Hackett ${ }^{50}$ não detectaram alterações significativas na velocidade de fluxo da artéria cerebral média nos primeiros três dias de órbita. Se considerarmos que a velocidade do sangue fornece uma razoável estimativa do fluxo nas situações em que fluxo e pressão não sofrem mudanças bruscas ${ }^{51}$, os dados de Bagian e Hackett sugerem que o fluxo cerebral não se altera no ambiente microgravitacional de maneira importante. Sinalizando nesta direção, um estudo de Gazenko e Ilyin ${ }^{52}$ em macacos resus do programa Cosmos não detectou mudanças na hemodinâmica carotídea durante a primeira semana no espaço. Por outro lado, estudos de impedância e Doppler carotídeo têm mostrado, com freqüência, aumento da pulsatilidade do fluxo cerebral, do volume líquido craniano e da resistência ao escoamento venoso em astronautas nos primeiros sete dias em $0 \mathrm{G}^{53-56}$.

No caso da simulação por HDT, Kawai e cols. ${ }^{57}$ relataram aumento da velocidade média do fluxo na artéria cerebral média nas primeiras $24 \mathrm{~h}$ de inclinação a $6^{\circ}$, sugerindo aumento da pressão nas artérias cerebrais. Em outro estudo, com a mesma metodologia (Doppler transcraniano) ${ }^{58}$, a velocidade de fluxo naquela artéria não se mostrou alterada com $24 \mathrm{~h}$ de HDT a $10^{\circ}$. Entretanto, foi observada concomitantemente uma redução do diâmetro das artérias retinianas, indicando vasoconstrição, provavelmente causada pela autorregulação.

É bastante provável que a circulação cerebral desenvolva mecanismos de aclimatação já nas primeiras semanas em microgravidade. No primeiro dia após o regresso de missões de 2 a 18 dias, a inclinação dos cosmonautas a $30^{\circ} \mathrm{com}$ cabeça para baixo $\left(\mathrm{HDT}\right.$ a $\left.30^{\circ}\right)$ promoveu um enchimento do pulso cerebral $23 \%$ menor do que o observado antes do vôo, alteração esta que se normalizou por volta do $7^{\circ}$ dia pós-vôo ${ }^{10}$.

Dados relativos a microcirculação craniana também sugerem aumento da pressão das artérias cranianas. Kirsch e cols. ${ }^{59}$ demonstraram um aumento da espessura cutânea na testa de um cosmonauta russo durante vôo orbital de nove dias, o que veio confirmar relatos freqüentes e evidências fotográficas de edema facial nos primeiros dias no espaço ${ }^{1,10,11,47}$. Este edema poderia ser explicado por uma elevação da pressão capilar que ocorreria em função dos aumentos previstos das pressões arterial e venosa (fig. 2). Coerentemente, no modelo HDT a $6^{\circ}$ em humanos, a pressão capilar, medida diretamente nos capilares labiais, apresentou-se elevada já aos 30min de inclinação, mantendo-se significativamente acima $(5-6 \mathrm{mmHg})$ dos valores controles nas $8 \mathrm{~h}$ de duração do experimento ${ }^{8}$. Além disso, está bem estabelecido que os mecanismos de proteção contra edema da microcirculação craniana são menos eficazes do que os dos membros inferiores ${ }^{5,60,61}$ (fig. 6).

\section{Controle geral da circulação em 0G}

Do ponto de vista do controle geral da circulação, chamam a atenção as alterações relativamente discretas dos principais parâmetros circulatórios na adaptação aguda a 0G. Devido às dificuldades técnicas e logísticas mencionadas anteriormente, a adaptação desses sistemas à microgravidade permanece ainda pouco conhecida. A maioria da informações provém da análise das respostas de freqüência cardíaca, pressão arterial e níveis hormonais obtidas durante a atividade normal dos astronautas ou em testes específicos, tais como o exercício físico e o teste da pressão negativa aplicada à região inferior do corpo (lower body negative pressure).

Com relação à freqüência cardíaca, os resultados são bastante contraditórios. De acordo com os levantamentos

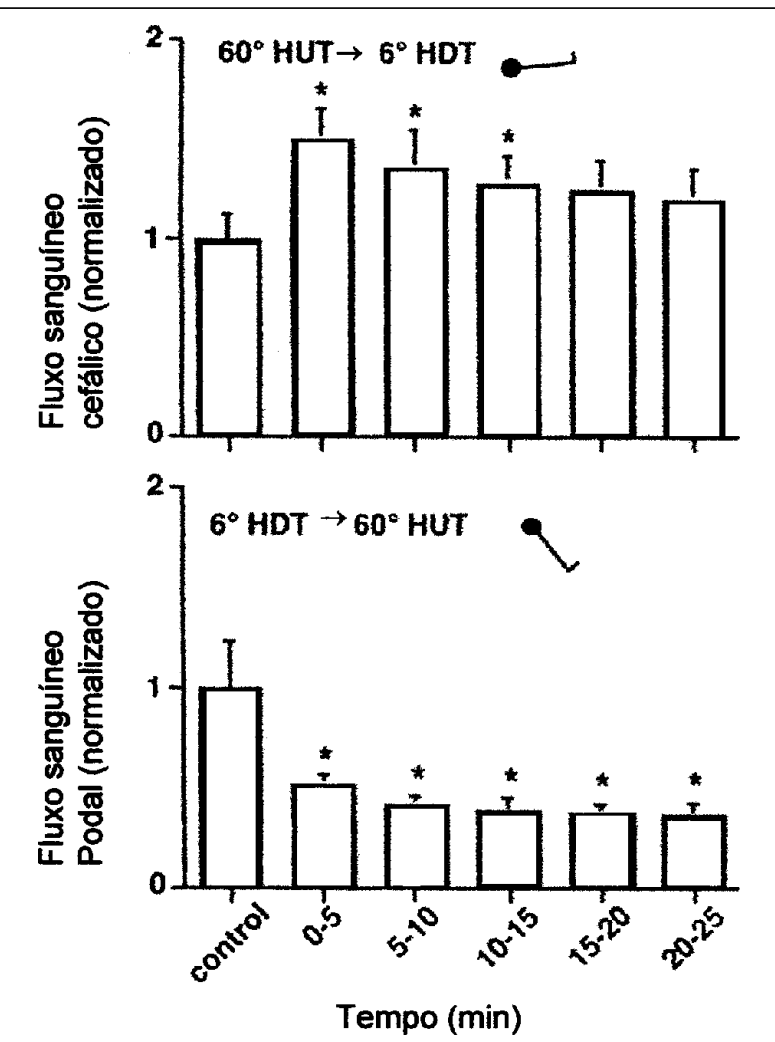

Fig. 6 - Efeitos da inclinação sobre o fluxo sangüíneo microvascular. Observe o aumento do fluxo cefálico na passagem de $60^{\circ} \mathrm{HUT}$ (head up tilt) para $6^{\circ} \mathrm{HDT}$ ( head down tilt). Por outro lado, quando os indivíduos foram inclinados de $6^{\circ} \mathrm{HDT}$ para $60^{\circ} \mathrm{HUT}$, o fluxo nos pés se mostrou reduzido, sugerindo a presença de um poderoso mecanismo regulador nos membros inferiores. (Reproduzido com autorização e modificado de Aratow, Hargens, Meyer \& Arnaud: Postural responses of head and foot cutaneous microvascular flow and their sensitivity to bed rest. Aviat Space Environ Med 1991; 62: 246-51). 
de Charles e Lathers ${ }^{11}$ e Fritsch-Yelle e cols. ${ }^{62}$ dos projetos Mercury, Gemini, Skylab e Salyut, medidas realizadas nas primeiras semanas no espaço mostraram aumento, redução ou ainda ausência de alterações da freqüência cardíaca em relação aos valores controles na Terra.

É provável que essas discrepâncias se devam principalmente à falta de homogeneidade nos protocolos experimentais como, por exemplo, falta de padronização dos horários e dos níveis de atividade física. Muitíssimo importante é o fator psicológico, principalmente em função do estresse presente em várias situações a bordo, inclusive durante a realização dos próprios experimentos. Como exemplo típico da influência emocional é citado o caso dos primeiros cosmonautas soviéticos participantes de missões solitárias, nos quais a freqüência cardíaca subia 50 a $100 \%$ na primeira órbita. Entretanto, nas mesmas condições, mas voando a três, o aumento da freqüência cardíaca foi de apenas 5 a $35 \%$ em relação ao controle pré-lançamento ${ }^{1}$.

Tentando contornar as causas da variabilidade, Fritsch-Yelle e cols. ${ }^{62}$ mediram a freqüência cardíaca e a pressão arterial de astronautas homens, com idade de $35 \pm 5$ anos, respectivamente por monitores Holter e aparelhos de pressão de ausculta automática, durante períodos de $24 \mathrm{~h}$, antes, durante e após missões de 5-10 dias do ônibus espacial americano. Como mostra a figura 7 , a freqüência cardíaca e a pressão diastólica no período de vigília apresentaram-se significativamente diminuídas no espaço em relação aos valores pré-lançamento, indicando provavelmente uma redução da atividade simpática. Esta redução, por sua vez, poderia ser explicada pela ausência de variações abruptas no retorno venoso (e conseqüentemente na pressão arterial) decorrentes de mudanças posturais no espaço, ao contrário do que ocorre em gravidade normal. No mesmo estudo, também a variabilidade da freqüência cardíaca e da pressão arterial mostrou-se reduzida durante a vigília. Previamente, a redução da freqüência cardíaca nos primeiros dias no espaço fora demonstrada em macacos com registro contínuo do eletrocardiograma ${ }^{63,64} \mathrm{e} \mathrm{ratos}^{65}$.

Uma das alterações cardiovasculares mais importantes - senão a principal - gerada pelo ambiente microgravitacional, é a intolerância ortostática apresentada pelos astronautas no retorno à Terra e se caracteriza, de modo semelhante ao observado em pacientes acamados por vários dias ${ }^{3,66}$, por hipotensão, taquicardia e tendência a síncope, quando o indivíduo assume a posição ereta. A intensidade do fenômeno pode ser percebida pelo estudo de Bungo e cols. ${ }^{67} \mathrm{em}$ nove astronautas procedentes de missões de dois a oito dias, não submetidos a quaisquer medidas preventivas: $1 \mathrm{a} 2 \mathrm{~h}$ após o pouso, a aplicação de um teste passivo de tolerância ortostática de $5 \mathrm{~min}$ (permanecer de pé 5 min após vários minutos em posição supina) promoveu um aumento de $47 \%(75 \rightarrow$ $110 \mathrm{bpm})$ na freqüência cardíaca e queda de $7 \%(96 \rightarrow$ $89 \mathrm{mmHg}$ ) na pressão arterial média, resultados estes bastante diferentes dos obtidos anteriormente aos vôos (freqüência: $57 \rightarrow 70 \mathrm{bpm}$; pressão: $84 \rightarrow 90 \mathrm{mmHg}$ ).

Para missões de curta duração, parece que a intensida-

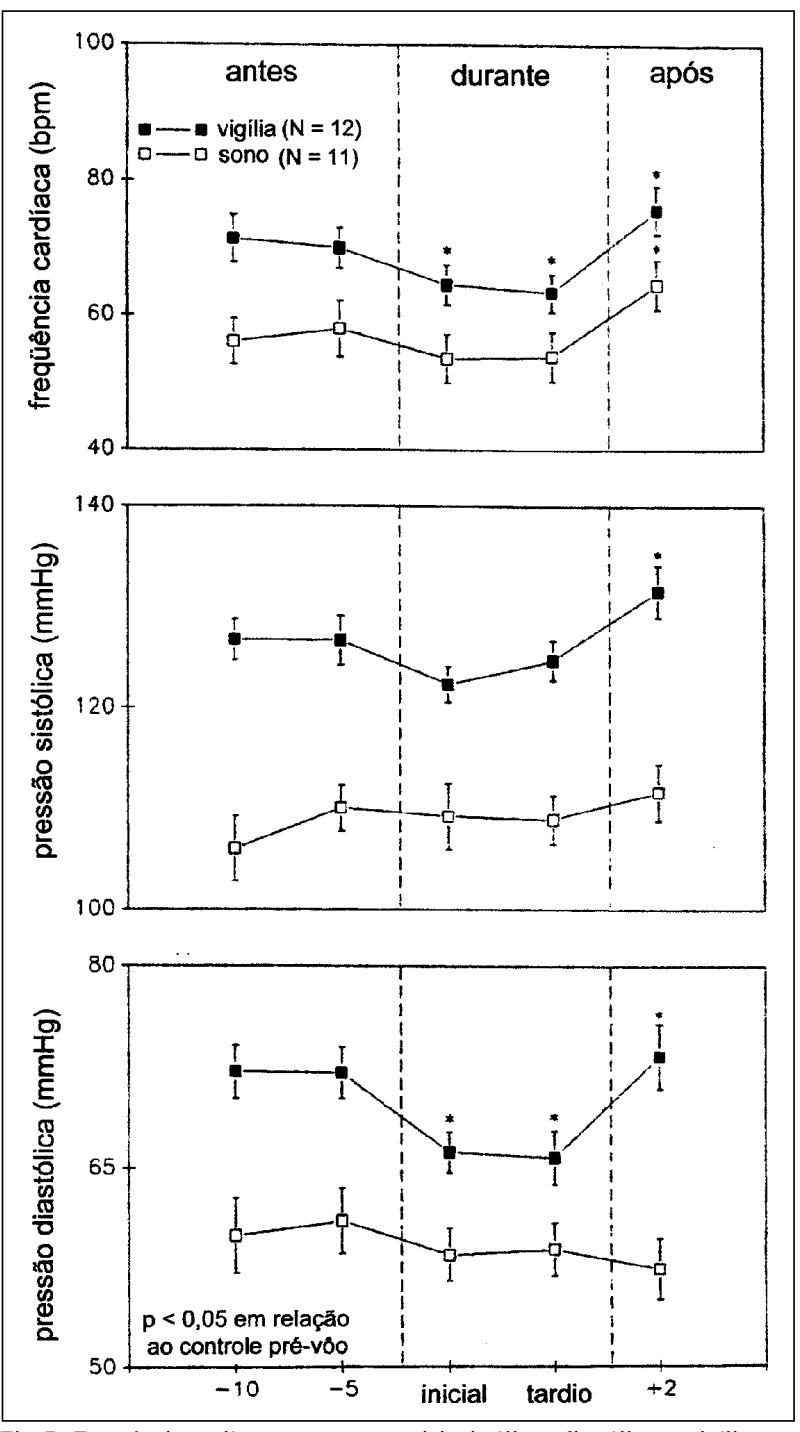

Fig. 7 - Freqüência cardíaca e pressões arteriais sistólica e diastólica na vigília e no sono em 12 astronautas do sexo masculino participantes de missões de 5 a 10 dias no ônibus espacial. Os parâmetros foram medidos duas vezes antes do vôo, duas durante o vôo e uma após a aterrissagem. A freqüência foi obtida por monitoração Holter e a pressão arterial por aparelhos de ausculta automática. Os valores indicam a média \pm 0 erro padrão. (Reproduzido com autorização de Fritsch-Yelle, Charles, Jones \& Wood: Microgravity decreases heart rate and arterial pressure in humans. J Appl Physiol 1996; 80: 910-4).

de da intolerância ortostática se correlaciona com o tempo de permanência no espaço. Segundo o levantamento de Charles \& Lathers ${ }^{11}$ das missões americanas entre 1962 e 1985, o incremento da freqüência cardíaca em resposta a mudança brusca do decúbito para a posição ereta no $1^{\circ}$ dia do regresso cresceu progressivamente de pouco menos de $20 \%$ nos vôos de até $24 \mathrm{~h}$ para cerca de $47 \%$ nos de quatro dias e $65 \%$ nos de oito dias (valores em relação aos controles pré-vôo).

A avaliação da intolerância ortostática pode ser feita no próprio ambiente espacial com a utilização do teste de lower body negative pressure (LBNP). Neste caso, o cosmonauta é introduzido, da cintura para baixo, em uma câmara de vácuo, a qual é selada à cintura do mesmo por meio de um anel de borracha ou plástico presente em sua abertura. A aplica- 
ção de 40 a 50mmHg de pressão negativa dentro da câmara (LBNP) equivale, em termos de dilatação venosa e respostas reflexas de pressão arterial e freqüência cardíaca, ao estresse cardiovascular de assumir a posição ortostática na Terra ${ }^{1,3}$.

A despeito da implementação sistemática de medidas preventivas há mais de 15 anos, a intolerância ortostática ainda constitui um problema para uma parcela significativa de astronautas. Segundo Jones e Charles ${ }^{68}$, quatro entre 25 participantes de missões do ônibus espacial sofreram queda igual ou superior a $25 \mathrm{mmHg}$ na pressão sistólica, e cinco apresentaram freqüência acima de $160 \mathrm{bpm}$ na primeira tentativa de se manter de pé após o pouso. Mais recentemente, Buckey e cols. ${ }^{69}$ relataram que nove entre 14 astronautas recém-chegados de missões curtas (9-14 dias) não suportaram um teste passivo de tolerância ortostática de $10 \mathrm{~min}$ após $29 \mathrm{~min}$ em posição supina.

Os mecanismos responsáveis pela intolerância ortostática não são plenamente conhecidos. A redução do volume plasmático tem sido apontada como um dos principais determinantes desta síndrome ${ }^{5,6}$. Entretanto, sabe-se que perdas agudas de 10-15\% da volemia (semelhante ao volume perdido após uma semana no espaço) ${ }^{29,31-33}$, não levam geralmente a quadros clínicos de intolerância ortostática da mesma intensidade ${ }^{29,70}$. Além disso, no modelo HDT, demonstrou-se que a restauração do estado volêmico não impede completamente o desenvolvimento da intolerância ortostática $^{22}$.

Hipoteticamente, alterações funcionais e estruturais dos vasos dos membros inferiores poderiam também contribuir para o quadro de intolerância ortostática por modificar a complacência venosa, a permeabilidade capilar ou a resistência arterial. Partindo do princípio de que a complacência venosa esteja realmente aumentada ${ }^{1,30}$, a passagem para a postura ereta levaria imediatamente ao armazenamento de sangue nos membros inferiores, o que acentuaria a redução do retorno venoso causada pela hipovolemia. Este efeito poderia ainda ser amplificado por um aumento da permeabilidade capilar, conforme sugerido pela presença de petéquias hemorrágicas em astronautas do Skylab ${ }^{1} \mathrm{e}$ edema e extravasamento de hemácias de membros posteriores em ratos do projeto Cosmos ${ }^{71}$. No entanto, a avaliação indireta da resposta vascular ao estresse gravitacional mostrou resultados conflitantes: testes de head up tilt (o inverso de HDT) aplicados em astronautas do projeto Gemini logo após o regresso produziram aumentos de 12 a $82 \%$ no volume da panturrilha ${ }^{1}$; por outro lado, astronautas recém-chegados das missões Apollo e de vôos de 6-9 dias no ônibus espacial apresentaram respectivamente diminuição ou ausência de alteração do volume da panturrilha quando submetidos ao teste de LBNP em posição supina ${ }^{1,66}$.

Na última década, surgiram trabalhos indicando que, pelo menos em parte, a intolerância ortostática estaria relacionada a alguma disfunção autonômica induzida pela microgravidade. Parte destas indicações veio de estudos sobre a resposta cardíaca do reflexo barorreceptor carotídeo avaliada através da relação sigmoidal entre o intervalo R-R do eletrocardiograma e a pressão de distensão carotídea (gerada pela aplicação de pulsos de pressão em torno do pesco- ço) ${ }^{72,73}$. De modo geral, os resultados foram semelhantes nos dois trabalhos e revelaram, no dia da aterrissagem ( $v s$ controle pré-vôo), deslocamento da curva do reflexo para baixo no eixo R-R, acompanhado de diminuição de sua inclinação máxima e do ponto operacional do reflexo (fig. 8). No conjunto, além de mostrar uma freqüência cardíaca aumentada para uma dada pressão de distensão, estes resultados sugerem menor capacidade relativa de tamponamento do reflexo barorreceptor carotídeo para estímulos hipotensores ${ }^{72}$. Uma vez que o intervalo R-R se correlaciona linearmente com a descarga vagal para o coração ${ }^{74}$, postulou-se que o distúrbio autonômico seria causado por alteração do componente parassimpático do reflexo ${ }^{72,73}$. Interessantemente, a mesma avaliação do reflexo barorreceptor carotídeo já havia sido realizada no modelo de simulação HDTa $6^{075}$, revelando praticamente os mesmos resultados.

Outra perspectiva foi aberta no estudo de Buckey e cols. ${ }^{69}$ dos parâmetros cardiovasculares de 14 astronautas durante um stand test de 10min realizado no dia do pouso, após um período de 10 a 14 dias em órbita. Como nove indivíduos não suportaram terminar o teste (não-finalizadores), os autores procuraram comparar os resultados destes com os dos finalizadores e verificaram que os dois grupos apresentavam redução do volume sistólico, aumento da freqüência cardíaca e queda do débito cardíaco de intensidade bastante semelhante. Entretanto, a resistência vascular periférica dos finalizadores mostrou-se aumentada de $32 \%$ em relação ao próprio controle pré-vôo, ao passo que nos nãofinalizadores este parâmetro praticamente não se alterou, indicando uma resposta vasoconstritora insuficiente. É importante mencionar que, no regresso de missões de curta

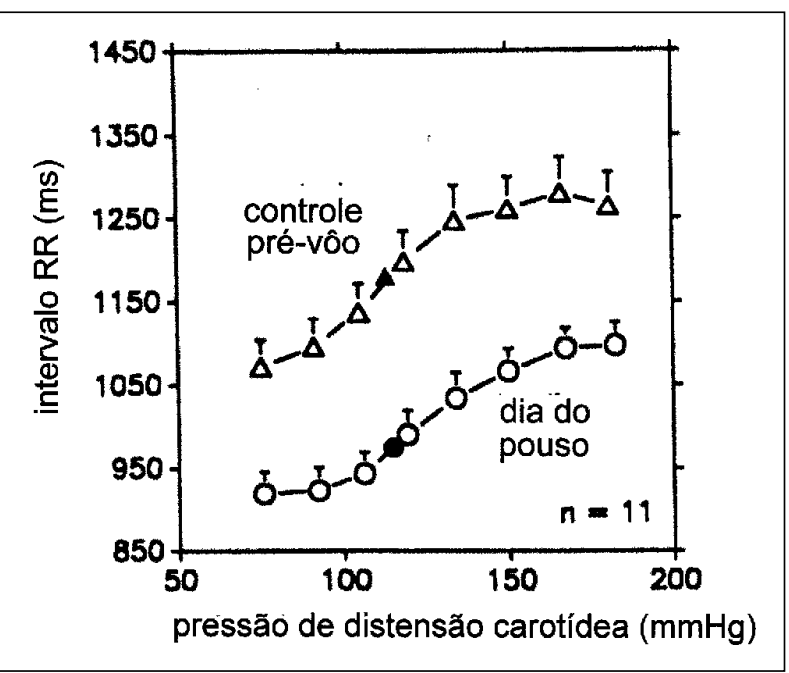

Fig. 8 - Relação entre o intervalo RR e a pressão de distensão carotídea antes do vôo e no dia da aterrissagem. Os símbolos fechados representam a posição dos pontos operacionais. Observe que o ponto operacional [definido como: (intervalo RR sob pressão de $0 \mathrm{mmHg}$ em torno do pescoço-intervalo RR mínimo) / faixa dos intervalos

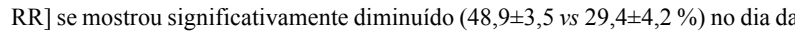
chegada $(\mathrm{N}=11)$. A inclinação máxima e a faixa de operação do reflexo apresentaram uma tendência à queda $(5,0 \pm 1,0$ vs $3,4 \pm 0,5 \mathrm{~ms} / \mathrm{mmHg} ; 243 \pm 47 v s 182 \pm 25 \mathrm{~ms})$ que se confirmou $(\mathrm{P}<0,05)$, para ambos os parâmetros, no dia seguinte com o aumento do número de indivíduos estudados $(\mathrm{N}=12)$. (Reproduzido com autorização e modificado de Fritsch, Charles, Bennett, Jones \& Eckberg: Short-duration spaceflight impairs human carotid baroreceptor-cardiac reflex responses. J Appl Physiol 1992; 73: 664-71). 
duração, os níveis plasmáticos de catecolaminas estão aumentados tanto na posição supina quanto na ortostática ${ }^{73,76}$, estando também aumentada a excreção renal destes hormônios ${ }^{77}$. Estas respostas são coerentes com a hipovolemia induzida pela microgravidade. Por outro lado, no modelo HDT a $6^{\circ}$ (14 dias), Convertino e cols. ${ }^{78}$ mostraram uma responsividade aumentada dos $\beta$-adrenoceptores, o que poderia contribuir para o aumento da freqüência cardíaca e a atenuação da resposta vasoconstritora característicos da intolerância ortostática.

\section{Agradecimentos}

Ao Prof. Roberto Takashi Sudo do Depto. de Farmacologia Básica e Clínica da UFRJ, pela revisão científica è̀ Dra. Maria da Conceição de Brito Magalhães pela revisão gramatical.

Dedicamos este artigo ao Prof. Ronaldo Rogério de Freitas Mourão, expoente da astronomia nacional, pelo incansável trabalho de divulgação da astronomia e astronáutica em nosso país.

\section{Referências}

1. Watenpaugh DE, Hargens AR. The cardiovascular system in microgravity. In: Fregly MJ, Blatteis CM (eds.). Handbook of Physiology. Enviromental Physiology. American Physiological Society. Nova York: Oxford, 1996; vol. 1, cap. 29: 631-74.

2. Burton RR, Smith AH. Adaptation to acceleration environments. In: Fregly MJ, Blatteis CM (eds.). Handbook of Physiology. Environmental Physiology. American Physiological Society. Nova York: Oxford, 1996; vol. 2, cap. 40: 943-70.

3. Blomqvist RJ, Stone HL. Cardiovascular adjustments to gravitational stress. In: Sheperd JT, Abboud FM (eds.). Handbook of Physiology. The Cardiovascular System. American Physiological Society. Baltimore: Waverly, 1983; vol. 3, cap. 28: 1025-63.

4. Hargens AR, Watenpaugh DE, Breit GA. Control of circulatory function in altered gravitational fields. Physiologist 1992; 35(suppl): S80-3.

5. Hargens AR, Watenpaugh DE. Cardiovascular adaptation to spaceflight. Med Sci Sports Exerc 1996; 28: 977-82.

6. Vernikos J. Human physiology in space. Bioessays 1996; 18: 1029-37.

7. Gazenko OG, Grigor'ev AI, Egorov AD. Physiological effects of weightlessness on humans under space flight conditions. Human Physiol 1997; 2: 248-55.

8. Parazynsky SE, Hargens AR, Tucker B, Aratow M, Styf J, Crenshaw A. Transcapillary fluid shifts in tissues of the head and neck during and after simulated microgravity. J Appl Physiol 1991; 71: 2469-75.

9. Levick JR, Michel CC. The effects of position and skin temperature on the capillary pressures in the fingers and toes. J Physiol 1978; 274: 97-109.

10. Gazenko OG, Genin AM. Summary of medical investigations in the U.S.S.R. manned space missions. Acta Astronautica 1981; 8: 907-17.

11. Charles JB, Lathers CM. Cardiovascular adaptation to spaceflight. JClin Pharmacol 1991; 31: 1010-23.

12. Buckey JC, Gaffney FA, Lane LD, Levine BD, Watenpaugh DE, Blomqvist CG. Central venous pressure in space. N Engl J Med 1993; 328: 1853-4.

13. Buckey JC, Gaffney FA, Lane LD, et al. Central venous pressure in space. J Appl Physiol 1996; 81: 19-25.

14. Johns JP, Vernalis MN, White CD, Karemaker JM, Latham RD. Echocardiographic evaluation of cardiac function during parabolic flight. Physiologist 1992; 35(suppl): S117-8.

15. Lathers CM, Charles JB, Elton KF, et al. Acute hemodynamic responses to weightlessness in humans. J Clin Pharmacol 1989; 29: 615-27.

16. Mukai CN, Lathers CM, Charles JB, Bennett BS, Igarashi M, Patel S. Acute hemodynamic responses to weightlessness during parabolic flight. J Clin Pharmacol 1991; 31: 993-1000.

17. Baish F, Beck L. Body impedance measurement during SpaceLab Mission D1. Physiologist 1987; 30(suppl): S47-8.

18. Kirsch KA, Rocker L, Gauer OH, et al. Venous pressures in man during weightlessness. Science 1984; 225: 218-9.

19. Kirsch KA, Haenel F, Rocker L. Venous pressure in microgravity. Naturwissenschaften 1986; 73: 447-9.

20. Foldager N, Andersen TAE, Jessen FB, et al. Central venous pressure in humans during microgravity. J Appl Physiol 1996; 81: 408-12.

21. Nixon JV, Murray RG, Bryant C, et al. Early cardiovascular adaptation to simulated zero gravity. J Appl Physiol 1979; 46: 541-8.

22. Blomqvist CG, Nixon JV, Johnson RL Jr, Mitchell JH. Early cardiovascular adaptation to zero gravity simulated by head-down tilt. Acta Astronautica 1980; 7 : 543-53.

23. Gaffney FA, Nixon JV, Karlson ES, Campbell W, Dowley ABC, Blomqvist CG. Cardiovascular deconditioning produced by 20 hours of bedrest with headdown tilt $\left(-5^{\circ}\right)$ in middle-aged healthy men. Am J Cardiol 1985; 56: 634-8.
24. Schutten HJ, Johannessen AC, Torp-Pedersen C, Sander-Jensen K, Bie P, Warberg J. Central venous pressure - a physiological stimulus for secretion of atrial natriuretic peptide in humans? Acta Physiol Scand 1987; 131: 265-72.

25. Norsk P, Foldager N, Bonde-Petersen F, Elmann-Larsen B, Johansen TS. Central venous pressure in humans during short periods of weightlessness. J Appl Physiol 1987; 63: 2433-7.

26. Katkov VE, Kakurin LI, Chestukhin VV, Kirsch K. Central circulation exposure to 7-day microgravity (head-down tilt, immersion, space flight). Physiologist 1987; 30(suppl): S-36-41.

27. Estenne M, Gorini M, van Muylen A, Ninane V, Paiva M. Rib cage shape and motion in microgravity. J Appl Physiol 1992; 73: 946-54.

28. White RJ, Blomqvist CG. Central venous pressure and cardiac function during spaceflight. J Appl Physiol 1998; 85: 738-46.

29. Convertino VA. Clinical aspects of the control of plasma volume at microgravity and during return to one gravity. Med Sci Sports Exerc 1996; 28(suppl.): S45-52.

30. Watenpaugh DE, Buckey JC, Lane LD, et al. ASGSB Bull 1992; 6: 35.

31. Leach CS, Jonhson PC. Influence of space flight on erythrokinetics in man. Science 1984; 225: 216-8.

32. Udden MM, Driscoll TB, Pickett MH, Leach-Huntoon CS, Alfrey CP. Decreased production of red blood cells in human subjects exposed to microgravity. J Lab Clin Med 1995; 125: 442-9.

33. Alfrey CP, Udden MN, Leach-Huntoon C, Driscoll T, Pickett MH. Control of red blood cell mass in spaceflight. J Appl Physiol 1996; 81: 98-104.

34. Fortney SM, Hyatt KH, Vogel JM. Changes in body fluid compartments during a 28-day bed rest. Aviat Space Environ Med 1991; 62: 97-104.

35. Convertino VA, Tatro DL, Rogan RB. Renal and cardiovascular responses to water immersion in trained runners and swimmers. Eur J Appl Physiol 1993; 67: 507-12.

36. Convertino VA, Engelke KA, Ludwig DA, Doerr DF. Restoration of plasma volume after 16 days of head-down tilt induced by a single bout of maximal exercise. Am J Physiol 1996; 270: R3-10.

37. Gurovskiy NN, Yeremin AV, Gazenko OG, Yegorov AD, Bryanov II, Genin AM. [Medical investigations during flights of the spaceships "Soyuz-12", "Soyuz13", "Soyuz-14" and the Salyut-3 orbital stations]. Kosm Biol Aviakosm Med 1975; 9: 48-54.

38. Leach CS, Altchuler SI, Cintron-Trevino NM. The endocrine and metabolic responses to space flight. Med Sci Sports Med 1983; 15: 432-40.

39. Greenleaf JE. Problem: thirst, drinking behavior and involuntary dehydration. Med Sci Sports Exer 1992; 24: 645-56.

40. Moore TP, Thornton WE. Space shuttle inflight and postflight fluid shifts measured by leg volume changes. Aviat Space Environ. Med 1987; 58(suppl.): A91-6.

41. Thornton WE, Hedge V, Coleman E, Uri JJ, Moore TP. Changes in leg volume during microgravity simulation. Aviat Space Environ Med 1992; 63: 789-94.

42. Pourcelot L, Arbeille P, Pottier J-M, et al. Cardiovascular examination during STS S1 G Mission June. Proc 2nd Int Conf Space Physiol 1985; Toulouse: 13-7.

43. Pottier J-M, Arbeille P, PatatF, et al. Comparative study of the cardiovascular adaptation to zero g during 7 days in space. Physiologist 1988; 31(suppl): S14-5.

44. Sulzman FM, Ferraro JS, Fuller CA, et al. Thermoregulatory responses of rhesus monkeys during spaceflight. Physiol Behav 1992; 51: 585-91.

45. Winn HR, Dacey Jr RG, Mayberg MR. Cerebral circulation. In: Patton HD, Fuchs AF, Hille B, Scher AM, Steiner R (eds). Textbook of Physiology. Filadélfia: WB Saunders, 1989; vol. 2, cap. 49: 952-60.

46. Vorobyov EI, Gazenko OG, Genin AM, Egorov AD. Medical results of Salyut-6 manned space flights. Aviat Space Environ Med 1983; 54(suppl): S31-40. 
47. Grigoriev AI, Bugrov SA, Bogomolov VV, et al. Medical results of the MIR yearlong mission. Physiologist 1991; 34(suppl): S44-8.

48. Draeger J, Schwartz R, Groenhoff S, Stern C. Self-tonometry under microgravity conditions. Clin Invest 1993; 71: 700-3.

49. Bondar RL, Kassam SF, Dunphy PT, Bennet BS, Johnston KW. Cerebral blood flow velocities by transcranial Doppler during parabolic flight. J Clin Pharmacol 1991; 31: 915-9.

50. Bagian JP, HackettP. Cerebral blood flow: comparison of ground-based and spaceflight data and correlation with space adaptation syndrome. J Clin Pharmacol 1991; 31: 1036-40

51. Kontos HA. Validity of cerebral arterial blood flow calculation from velocity measurements. Stroke 1989; 20: 1-3.

52. Gazenko OG, Ilyin EA. Physiological investigations of primates onboard biosatellites Cosmos-1514 and Cosmos-1667. Physiologist 1987; 30(suppl): S31-4

53. Moskalenko YE, Weinstein GB, Semernja VN. Investigation of human cerebral circulation in spaceflight conditions. Aviat Space Environ. Med 1975; 46 1023-6.

54. Pourcelot L, Arbeille P, Pottier J-M, et al. Ultrasonic study of early cardiovascular adaptation to zero gravity. Proc 2nd Eur Symp Life Sci Res Space (ESA SP212) 1984: 119-23

55. Yarullin K, Vasil'yeva TD, Turchaninova VF, Sokolova IV, Vikharev ND. [Compensatory-adaptive reactions of regional hemodynamics to weightlessness during a long space flight]. Kosm Biol Aviakos Med 1984; 18: 22-8.

56. Turchaninova VF, Egorov AD, Domracheva MV. [Central and regional hemodynamics in long space flights]. Kosm Biol Aviakos Med 1989; 23: 19-26.

57. Kawai YK, Murthy G, Watenpaugh DE, et al. J Appl Physiol 1993; 74: 3036-51

58. Frey MAB, Mader TH, Bagian JP, Charles JB, Meehan RT. Cerebral blood velocity and other cardiovascular responses to 2 days of head-down tilt. J Appl Physiol 1993; 74: 319-25.

59. Kirsch KA, Baartz F-J, Gunga H-C, Rocker L, Wicke HJ, Bunsch B. Fluid shifts into and out of superficial tissues under microgravity and terrestrial conditions. Clin Investig 1993; 71: 687-9.

60. Williamson JR, Vogler NJ, Kilo C. Regional variations in the width of the basement membrane of muscle capillaries in man and giraffe. Am J Pathol 1971; 63:359-76.

61. Aratow M, Hargens AR, Meyer J-U, Arnaud SB. Postural responses of head and foot cutaneous microvascular flow and their sensitivity to bed rest. Aviat Space Environ Med 1991; 62: 246-51.

62. Fritsch-Yelle JM, Charles JB, Jones MM, Wood ML. Microgravity decreases hear rate and arterial pressure in humans. J Appl Physiol 1996; 80: 910-4.
63. Blostin R, Milhaud C, Cailler B, et al. Cosmos 1514 flight: study of Rhesus monkey ECG. Proc 2nd Int Conf Space Physiol, Toulouse, 1985: 217-23 (ESA SP-237).

64. Iljin EA, Korolkov VI, Kozlovskaya IB, Lobachik VI, Truzhennikov AN. The monkey in space flight. Physiologist 1991; 34(suppl): S49-51.

65. Schatte C, Grindeland R, Callahan P, Berry W. Animal studies on Spacelab-3 Proc 2nd Int Conf Space Physiol (ESA SP-237) 1985, Toulouse: 197-202.

66. Fortney SM, Schneider VS, GreenleafJE. The physiology of bed rest. In: Fregly MJ, Blatteis CM (eds.). Handbook of Physiology. Environmental Physiology. American Physiological Society. Nova York: Oxford, 1996; vol. 2, cap. 39: 889-939.

67. Bungo MW, Charles JB, Johnson Jr PC. Cardiovascular deconditioning during space flight and use of saline as a countermeasure to orthostatic intolerance. Avia Space Environ Med 1985; 56: 985-90.

68. Jones MM, Charles JB. Human blood pressure and heart rate changes during space shuttle landing and crew egress. FASEB J 1993; 7: A665.

69. Buckey JC, Lane LD, Levine BD, et al. Orthostatic intolerance after space-flight J Appl Physiol 1996; 81: 7-18.

70. Perhonen MA, Zuckerman RN, Levine BD. Deterioration of left ventricula chamber performance after bed rest: deconditioning or hypovolemia? Circulation 2001; 103: 1851-7.

71. Riley DA, Ilyina-Kakueva EI, Ellis S, Bain JLW, Slocum GR, Sedlak FR. Skeleta muscle fiber, nerve, and blood vessel breakdown in space-flown rats. FASEB 1990; 4: 84-91.

72. Fritsch JM, Charles JB, Bennett BS, Jones MM, Eckberg DL. Short-duration spaceflight impairs human carotid baroreceptor-cardiac reflex responses. J App Physiol 1992; 73: 664-71.

73. Fritsch-Yelle JM, Charles JB, Jones MM, Beightol LA, Eckberg DL. Spacefligh alters regulation of arterial pressure in humans. J Appl Physiol 1994; 77: 1776-83.

74. Katona PG, Poitras JW, Barnett GO, Terry BS. Cardiac vagal efferent activity and heart period in the carotid sinus. Am J Physiol 1970; 1030-7.

75. Convertino VA, Doerr DF, Eckberg DL, Fritsch JM, Vernikos-Danellis J. Headdown bed rest impairs vagal baroreflex responses and provokes orthostatic hypotension. J Appl Physiol 1990; 68: 1458-64.

76. Whitson PA, Charles JB, Williams WJ, Cintión M. Changes in sympathoadrena response to standing in humans after spaceflight. J Appl Physiol 1995; 79: 428-33.

77. Popova IA, Afonin BV, Davydova NA, Grigoriev AI. Hormonal regulation in space flights of varying duration. Physiologist 1987; 30(suppl): S42-4.

78. Convertino VA, Polet JL, Engelke KA, Hoffler GW, Lane LD, Blomqvist CG. Evidence for increased beta-adrenoceptor responsiveness induced by 14 days of simulated microgravity in humans. Am J Physiol 1997; 273: R93-9. 